\title{
ANÁLISE DA CAPACIDADE DE TRÁFEGO E NÍVEL DE SERVIÇO OPERACIONAL DE DIFERENTES ARRANJOS GEOMÉTRICOS PARA INTERSEÇÕES URBANAS UTILIZANDO MICROSIMULAÇÃO
}

\author{
Crhistian Emilio Ribeiro \\ Engenheiro Civil pela Universidade Federal do Espírito Santo \\ crhistianribeiroe@gmail.com \\ Antônio Luiz Caus \\ Universidade Federal do Espírito Santo \\ Departamento de Engenharia de Produção \\ al.caus@hotmail.com \\ Marta Monteiro da Costa Cruz \\ Universidade Federal do Espírito Santo \\ Departamento de Engenharia de Produção \\ mcruznpd@gmail.com \\ Leivisgton Jansen Silvestre Leitão \\ Instituto Federal do Espírito Santo \\ Coordenadoria de Estradas \\ jansen@ifes.edu.br
}

\begin{abstract}
RESUMO
Esse trabalho visa analisar o desempenho operacional da interseção entre as avenidas João Palácio e Norte Sul com as modificações viárias e de fluxo de veículos que acontecerão com a implantação do projeto de mergulhão elaborado pela Prefeitura Municipal da Serra. As análises foram embasadas nos resultados apresentados nas microsimulações de tráfego feitas com a utilização do software PTV Vissim. Foram avaliados dois cenários: o primeiro mantém a situação física da via atualmente com o volume de veículos projetado para o ano de 2033, enquanto o segundo cenário foi analisado no formato proposto pelo projeto elaborado pela Prefeitura com volume de veículos previsto para o ano de 2033. Os resultados das simulações mostraram que para as condições atuais e futuras, a nova geometria projetada para as avenidas apresenta níveis de serviço satisfatórios ao longo de toda sua extensão.
\end{abstract}

Palavra-chave: Microsimulação; Simulação de Tráfego; Intercessão urbana; Nível de serviço; PTV Vissim.

\begin{abstract}
The present work aims to analyze the level of service (LOS) of the intersections, located on the intersection between Norte Sul avenue and José Palácio avenue, considering the changes related on traffic and streets because of the new Project developed by Serra City
\end{abstract}


Hall. Two scenarios were studied: the first one maintains the physical conditions of the actual state for 2033 traffic; the second one presents the future situation after the execution of the project for 2033 traffic. Microsimulations results shows that the new geometry projected in the initial and future conditions of traffic shows satisfactory levels of service in all its extension.

Keywords: Microsimulation; Traffic simulation; Urban road intersection; Level of service; PTV Vissim.

\section{Como Citar:}

RIBEIRO, C. E.; CAUS, A. L.; CRUZ, M. M. C.; LEITÃO; L. J. S. Análise da capacidade de tráfego e nível de serviço operacional de diferentes arranjos geométricos para interseções urbanas utilizando microsimulação. In: SIMPÓSIO DE PESQUISA OPERACIONAL E LOGÍSTICA DA MARINHA, 19., 2019, Rio de Janeiro, RJ. Anais [...]. Rio de Janeiro: Centro de Análises de Sistemas Navais, 2019.

\section{INTRODUÇÃO}

O crescimento da frota de veículos em todo o Brasil vem sendo o centro de diversas discussões relativas às políticas de mobilidade urbana que devem ser adotadas e executadas de modo a garantir o direito de ir e vir dos cidadãos, presente na Constituição. Entre os anos de 2006 e 2016, houve crescimento de 72,24\% na frota de automóveis dos municípios da Grande Vitória (Cariacica, Fundão, Guarapari, Serra, Viana, Vitória e Vila Velha) de acordo com o Relatório de Estatística de Trânsito do Detran-ES (2016), atingindo o número de 480.468 automóveis. Somente no Município de Vitória, os 120.680 automóveis correspondem a um aumento de 29,73\% em relação à frota de 2006. Este crescimento leva à diminuição do nível de serviço das vias, que não são mais capazes de comportar o fluxo de maneira satisfatória, tanto para os condutores quanto para a cidade como um todo. Dessa forma, através da engenharia de tráfego, faz-se necessário o estudo de novas alternativas geométricas das vias atuais, de modo que se devolva à via o nível de serviço igual ou tão satisfatório quanto a de quando foi executada.

Este problema de estrangulamento na capacidade da via foi encontrado na interseção entre as Avenidas João Palácio e Norte Sul, no bairro Eurico Sales, Serra-ES. Assim sendo, este trabalho tem como objetivo simular o tráfego na interseção entre as avenidas João Palácio e Norte Sul com a atual geometria e com a geometria proposta pela Prefeitura Municipal da Serra, levando em consideração as viagens geradas pelo pólo gerador, o Shopping Mestre Álvaro. Foi utilizado o software de microsimulação de tráfego PTV Vissim (2018) para a análise do tráfego na geometria atual e na geometria projetada pela Prefeitura da cidade, ambos os cenários para o ano de 2033. Este artigo está estruturado nos seguintes capítulos: No capítulo 1, é apresentado o objetivo do artigo. No capítulo 2, são apresentados os conceitos fundamentais de microsimulação de tráfego. No capítulo 3, são apresentados os principais aspectos do cruzamento em análise. O capítulo 4 apresenta a solução proposta de alteração na geometria da interseção de modo a aumentar o nível de serviço da mesma. O capítulo 5 apresenta os cenários analisados, enquanto o capítulo 6 apresenta comparativamente os resultados das microsimulações realizadas em cada cenário. Por fim, o capítulo 7 apresenta a conclusão do estudo, estando as referências bibliográficas apresentadas no capítulo 8. 


\section{REFERENCIAL TEÓRICO}

A Engenharia Civil possui um grande leque de ramos de atuação e, dentre as opções, está a engenharia de tráfego. A engenharia de tráfego relaciona o planejamento com o desenho geométrico e com as operações de tráfego das vias ou estradas, suas redes, terminais, terrenos e empreendimentos adjacentes, incluindo a integração dos modos e tipos de transportes, proporcionando uma movimentação segura e eficiente nestes locais.

Portanto, o trabalho relacionado a esse campo de atuação não se finda quando da finalização da execução ou adequação de uma via. As cidades são dinâmicas, ou seja, a todo momento surgem novas demandas, bem como, novos empreendimentos são executados. A depender do porte do empreendimento executado e de sua localização, os órgãos responsáveis pelo controle de tráfego na região deverão observar a compatibilidade entre o modo como a via é operada e como ela virá a se comportar a partir da sua inauguração. $\mathrm{O}$ controle de operações semafóricas e a constante avaliação dos impactos causados por novas construções são de responsabilidade dos respectivos responsáveis pela via, a depender do nível de jurisdição a que está submetida. Portanto, verifica-se que há uma grande responsabilidade tanto na implantação quanto na manutenção e adequação de uma via ou malha viária a partir das modificações e diferentes usos a que as mesmas se submetem ao longo dos anos, sendo a simulação computacional uma maneira extremamente eficiente de se validar tomadas de decisão pelo corpo técnico responsável pela implantação ou modificação de uma via.

\subsection{SimulaçÃo de Tráfego}

A simulação de tráfego se utiliza de softwares que realizam cálculos de modo a replicar uma sequência de eventos hipotéticos na via estudada ao longo de determinado período, sendo uma técnica de modelagem e análise usada para avaliar e aprimorar os sistemas dinâmicos de todos os tipos (Harrell, et all, 2000). Desse modo, essa técnica também pode ser aplicada na engenharia de tráfego, normalmente utilizando modelos físicos, que apresentam em ambiente simulado (computador) e em escala reduzida, a reprodução do funcionamento do sistema em estudo, podendo ser realizada a partir de três abordagens: macroscópica, mesoscópica e microscópica. A abordagem microscópica, desenvolvida na década de 50, aprimorou as chamadas Leis de Sequência ou de Perseguição (Portugal, 2005). Nesse método, utilizado neste trabalho, é possível acrescentar um maior detalhamento dos veículos que serão estudados na seção de interesse de uma via, podendo atribuir aos mesmos diferentes valores de tamanho, velocidade e aceleração dos componentes. Portanto, o software de simulação a ser utilizado no estudo de caso pelo engenheiro de tráfego deve levar em consideração a geometria do local, a quantidade de variáveis que vão ser analisadas, o nível de detalhamento dos dados de saída do programa, o gargalo que o mesmo visa solucionar, assim como a técnica adotada para solucionar tal problema

A microsimulação pode ser utilizada para representar a formação e a descarga das filas nas interseções (Araújo e Neto, 2018), para análise do tráfego de pedestres em interseções semaforizadas (Martín, et al, 2019) e para verificação dos impactos causados nas condições ambientais em áreas urbanas em decorrência do tipo de operação utilizada na interseção de vias (Aguiar, et al, 2017). Portanto, se configura como uma ferramenta versátil e de grande auxílio para a tomada de decisões das partes envolvidas no projeto, caso tenha tido as suas variáveis bem calibradas e validadas, podendo ser utilizado como modelo válido do fenômeno (Sasaki, et al, 2017).

\subsection{CAPACIDAde E NíVEl DE SERVIÇo}

O objetivo da determinação da capacidade de uma via é quantificar o seu grau de suficiência para acomodar os volumes de trânsito existentes e previstos, permitindo a análise 
técnica e econômica de medidas que assegurem o escoamento daqueles volumes em condições aceitáveis (DNIT, 2006). A capacidade caracterizada como ideal pressupõe boas condições meteorológicas, ausência de incidentes que afetam o fluxo normal de veículos, boa condição operacional dos pavimentos flexíveis, somente veículos de passageiros no tráfego e outras características que aproximam o comportamento da via ao perfeito.

No entanto, a capacidade da via é um dado que não evidencia plenamente as condições de utilização da via pelos usuários, pois retorna apenas a quantidade de veículos que podem circular dentro de um determinado intervalo de tempo. A capacidade da via não leva em consideração a velocidade e o tempo de percurso, facilidade de manobras, segurança, conforto proporcionado aos usuários, entre outros fatores importantes para a total determinação da qualidade da via ao trânsito. Como forma de representar a qualidade da utilização da via pelos usuários, foi criado nos Estados Unidos, em 1965, através do Highway Capacity Manual (HCM), o conceito de níveis de serviço.

O conceito de nível de serviço de uma via possibilita avaliar o seu grau de eficiência na oferta em toda a variação de volume de tráfego que a mesma comporta. De acordo com o HCM, foram selecionados 6 (seis) níveis designados pelas seis primeiras letras do alfabeto. $\mathrm{O}$ nível $\mathrm{A}$ corresponde à melhor condição de operação, enquanto o nível $\mathrm{F}$ corresponde à condição de congestionamento completo. Entre estes dois extremos, situam-se os demais níveis.

\section{ESTUDO DE CASO}

O local do estudo foi escolhido devido aos conflitos de tráfego e perda do nível de serviço das vias, principalmente por conta das viagens com destino ao Shopping Mestre Álvaro e da expansão econômica do município de Serra ao longo dos últimos anos. O município de Serra teve um crescimento econômico acima da média quando comparado aos outros municípios da Região Metropolitana de Vitória, concentrando atualmente o maior parque industrial metropolitano e estadual (Câmara Municipal da Serra, 2005). Devido à essas características, o fluxo de veículos, inclusive de grande porte, que fazem o trajeto entre a cidade e a capital do estado através da Avenida Norte Sul é considerável e impactam diretamente nos níveis de serviço da interseção. Além disso, a Avenida Norte Sul corta grandes bairros residenciais ao longo de sua extensão, tais como Jardim Camburi e Jardim Limoeiro.

Por outro lado, a Avenida João Palácio realiza a conexão entre a BR 101 e a Avenida Norte Sul. O trecho da BR onde se origina a Avenida João Palácio possui um hospital de grande porte, uma unidade de saúde, uma grande área de eventos e um hotel (Figura 1). Portanto, existem diversos empreendimentos que geram viagens e que são capazes de influenciar o fluxo de veículos na via. Além disso, por se tratar de uma rodovia federal, existe o constante trânsito de veículos pesados. Dessa forma, diversos veículos de menor porte se deslocam da rodovia para a avenida Norte Sul como forma de evitar esse tipo de tráfego, gerando um aumento no fluxo na mesma, sentido Shopping Mestre Álvaro.

Com o exposto, a interseção entre as duas vias mencionadas vem apresentando retenções e tempos de espera que não são considerados ideais, aumentando o tempo das viagens dos veículos que por ali trafegam e causando transtornos aos condutores. 
Figura 1: Vista geral da área avaliada da intervenção e localização das avenidas de interesse

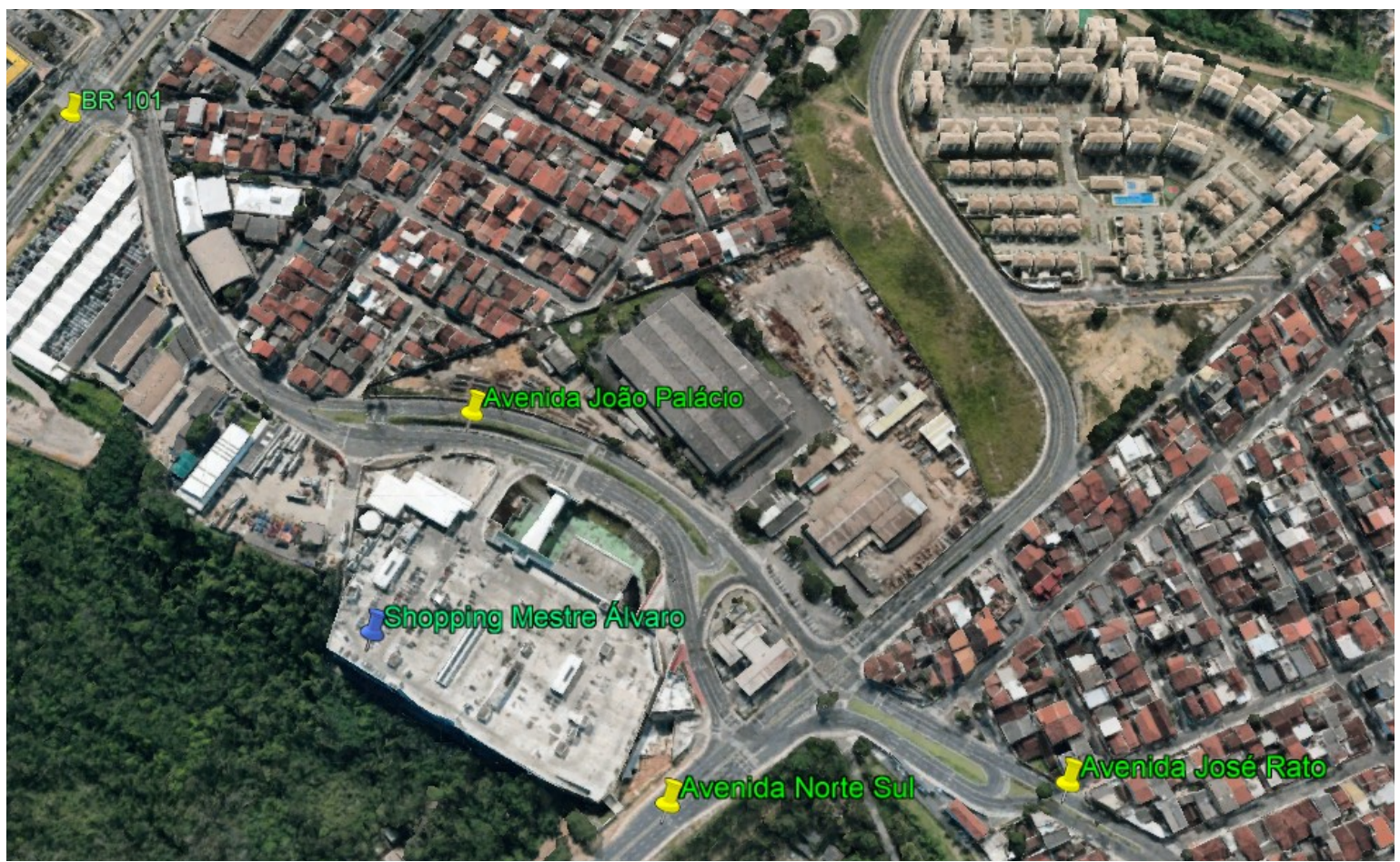

Fonte: Google Earth

\subsection{Dados de ConTAgem}

A contagem de veículos na interseção entre as Avenidas João Palácio e Norte Sul foi realizada para o Estudo de Impacto de Vizinhança (EIV) da Vale, elaborado em junho de 2016 e disponibilizado pela Prefeitura Municipal da Serra para a realização deste estudo, juntamente com os mapas de movimentos e das planilhas de contagem para cada movimento identificado na área de estudo.

Para a realização das simulações de diferentes arranjos geométricos das vias estudadas, foi definido que seriam utilizados os dados contidos entre 18:00 e 19:00 horas, por apresentarem os maiores valores de volume de veículos na região estudada.

\subsection{CiClos SEMAFóricos}

Os ciclos semafóricos da interseção estudada foram verificados em campo. Para a correta determinação dos ciclos utilizados atualmente nos semáforos do local, foram realizadas filmagens que possibilitaram a verificação minuciosa dos tempos empregados nas vias de interesse.

\subsection{CONVERSõES de Veículos}

As conversões dos veículos devem ser informadas ao software de modo que ele direcione um determinado fluxo para a sua realização. Essa informação é transmitida para o software através do percentual em relação do volume total de veículos que realiza determinada conversão. Dessa forma, fez-se necessário o cálculo probabilístico básico do percentual de veículos que realizariam cada uma das conversões a partir do seu ponto de entrada na rede do software.

Cabe ressaltar que o estudo de impacto de vizinhança disponibilizado para a realização deste trabalho contava com dados acerca do volume de motocicletas e bicicletas que transitavam no trecho. No entanto, o software PTV Vissim não é capaz de inserir motocicletas em suas simulações. Deste modo, fez-se a conversão das motos constantes nos dados de contagem em veículos de passeio através da razão 3:1, onde três motos equivalem a 
um carro. As bicicletas que foram levadas em consideração no EIV foram retiradas do quantitativo de veículos da rede a ser simulada, não possuindo influência ou participação nos cenários analisados.

\subsection{Transporte Público}

O PTV Vissim pode incluir na sua rede a ser simulada transportes públicos, que são inseridos de maneira diferenciada do restante do volume de veículos por possuírem características distintas como paradas em pontos, tempos de embarque e desembarque.

Em vistoria, foram levantadas as linhas de transporte público que transitam nas avenidas João Palácio e Norte Sul e, após consulta ao itinerário no site da empresa responsável para a verificação das rotas, os transportes públicos foram inseridos na rede.

\subsection{CREscimento da Frota}

As microsimulações da geometria atual e a sugerida pelo projeto da Prefeitura Municipal da Serra foram executadas para o ano horizonte de 2033.

Como os dados de contagem de veículos nas interseções são referentes ao ano de 2016, ano da realização do estudo de impacto de vizinhança, foi necessário realizar projeções de crescimento da frota de veículos para o ano de 2033 no município da Serra com base em dados do DENATRAN acerca da frota municipal por tipo de veículo entre os anos de 2008 e 2018, apresentado na Tabela 1.

Tabela 1: Frota de veículos do município de Serra entre 2008 e 2018

\begin{tabular}{cccc}
\hline Ano & Mês & Município & Total \\
\hline 2008 & set/08 & Serra & 95430 \\
\hline 2009 & mar/09 & Serra & 100502 \\
\hline 2009 & set/09 & Serra & 105878 \\
\hline 2010 & mar/10 & Serra & 112052 \\
\hline 2010 & set/10 & Serra & 118089 \\
\hline 2011 & mar/11 & Serra & 125417 \\
\hline 2011 & set/11 & Serra & 131636 \\
\hline 2012 & mar/12 & Serra & 138327 \\
\hline 2012 & set/12 & Serra & 145001 \\
\hline 2013 & mar/13 & Serra & 151158 \\
\hline 2013 & set/13 & Serra & 156480 \\
\hline 2014 & mar/14 & Serra & 162400 \\
\hline 2014 & set/14 & Serra & 167814 \\
\hline 2015 & mar/15 & Serra & 174016 \\
\hline 2015 & set/15 & Serra & 178084 \\
\hline 2016 & mar/16 & Serra & 181994 \\
\hline 2016 & set/16 & Serra & 185013 \\
\hline 2017 & mar/17 & Serra & 188405 \\
\hline 2017 & set/17 & Serra & 192064 \\
\hline 2018 & $\mathrm{mar} / 18$ & Serra & 196664 \\
\hline 2018 & set/18 & Serra & 200684 \\
\hline & & &
\end{tabular}

Fonte: DENATRAN (2018)

Para o ano horizonte de 2033, foi calculada a linha de tendência de crescimento da frota de veículos. Tomado como base os dados de veículos entre os anos de 2008 e 2018, a curva de crescimento da frota de veículos (Figura 2), se aproximou de um polinômio de 
segundo grau, com valor de $\mathrm{R}^{2}=0,9984$. O coeficiente de determinação, também chamado de $\mathrm{R}^{2}$, é uma medida de ajustamento de um modelo estatístico linear generalizado, em relação aos valores observados. $\mathrm{O} \mathrm{R}^{2}$ varia entre 0 e 1 , indicando, em percentagem, o quanto o modelo consegue explicar os valores observados.

Figura 2: Crescimento da frota de veículos no Município de Serra até 2033

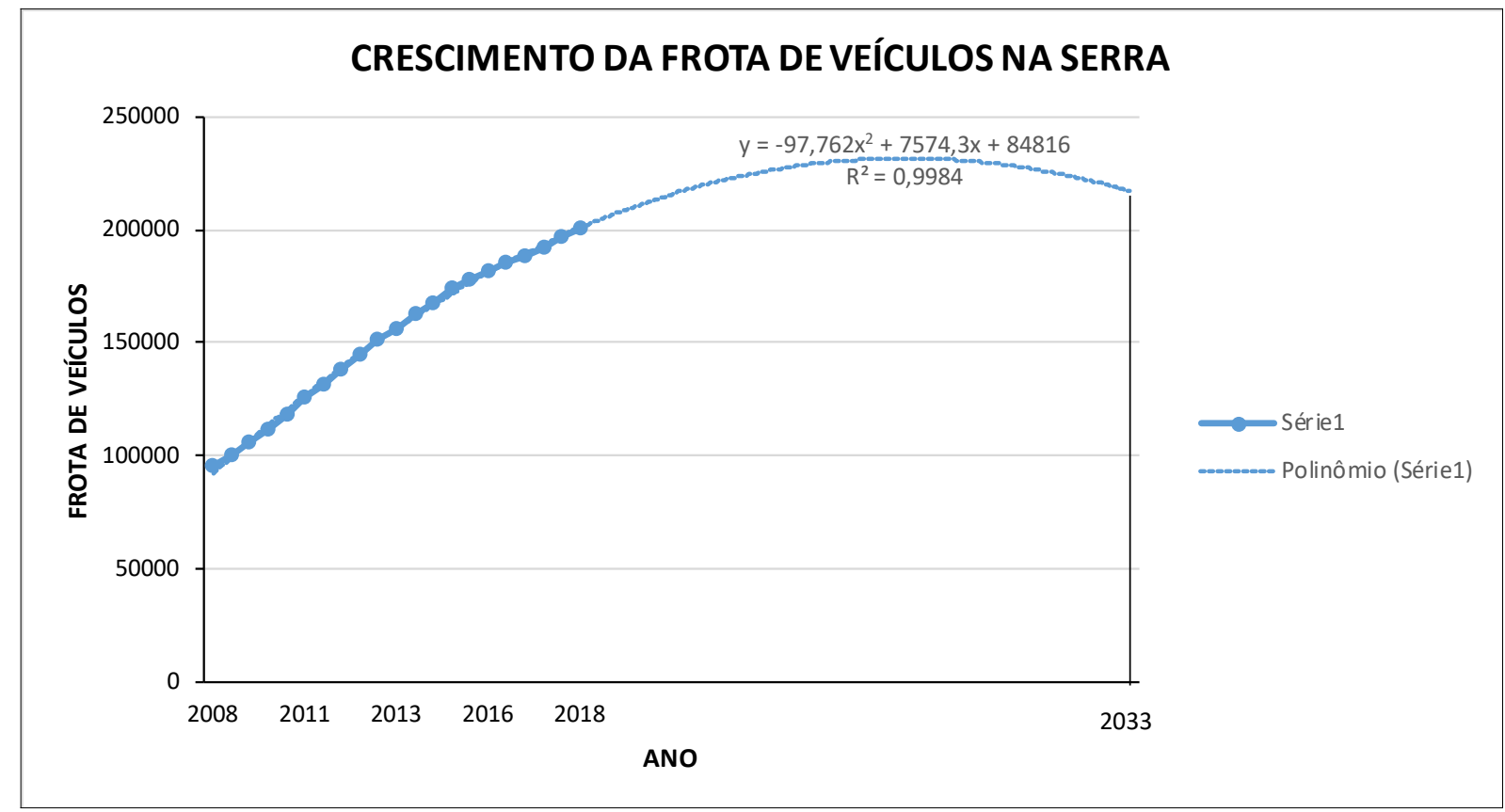

Fonte: $\mathrm{O}$ autor

O valor de x refere-se à localização do ponto a ser analisado. O mês de setembro de 2008, primeiro dado da série analisada, possuir valor de $x=1$, conforme se pode verificar nos dados da tabela 1. Já o mês de setembro do mesmo ano, possuir $\mathrm{x}=2$, enquanto o valor de $\mathrm{x}$ para março de 2009 é igual a 3 e assim por diante. Dessa forma, para setembro de 2033, obteve-se $\mathrm{x}=51$.

Tabela 2: Crescimento percentual da frota de veículos no Município de Serra em relação a 2016

\begin{tabular}{ccc}
\hline Ano & Frota (veículos) & $\begin{array}{c}\text { Crescimento em } \\
\text { relação à 2016 }\end{array}$ \\
\hline $\mathbf{2 0 1 6}$ & 185013 & - \\
\hline $\mathbf{2 0 1 8}$ & 200684 & $8,47 \%$ \\
\hline $\mathbf{2 0 3 3}$ & 216826 & $17,20 \%$ \\
\hline
\end{tabular}

Fonte: $\mathrm{O}$ autor

Dessa forma, o volume de veículos calculado através dos dados do Estudo de Impacto de Vizinhança disponibilizados pode ser acrescido dos percentuais calculados e apresentados na Tabela 2 para os anos analisados neste estudo, gerando a tabela 3, onde constam os dados dos inputs dos veículos no software. 
Tabela 3: Volume de veículos nas redes simuladas

\begin{tabular}{ccccc}
\hline \multicolumn{2}{c}{ Inputs de veículos na rede de simulação } \\
Movimento & Ponto & \begin{tabular}{c} 
Total \\
Hora(un \\
\cline { 2 - 4 }
\end{tabular} & $\begin{array}{c}\text { Total } \\
\text { Hora(un } \\
\text { ) }\end{array}$ & $\begin{array}{c}\text { Total } \\
\text { Hora(un) }\end{array}$ \\
\hline João Palácio (sentido Norte & ponto 20: A & 927 & 1005 & 1086 \\
Sul) & & & & \\
\hline Norte Sul (sentido Serra) & ponto 19: A & 1310 & 1421 & 1535 \\
\hline José Rato (sentido Shopping) & ponto 19: E & 928 & 1007 & 1088 \\
\hline Norte Sul (sentido Vitória) & Ponto 19: O & 1297 & 1407 & 1520 \\
\hline Saída Garagem 06 & Ponto 20: F & 98 & 107 & 115 \\
\hline Saída Garagem 07 & Ponto 20: K & 44 & 48 & 52 \\
\hline
\end{tabular}

Fonte: $\mathrm{O}$ autor

Cabe ressaltar que a curva obtida na Figura 2 não é conservadora, visto que possui um valor máximo seguido de decréscimo. Esse estudo considerou que as novas formas de locomoção praticadas atualmente podem vir a impactar na frota de veículos. Com o advento dos motoristas de aplicativo, além de outros aplicativos de carona solidária e o incentivo ao aluguel de bicicletas para locomoção no dia a dia, a necessidade das pessoas possuírem um veículo próprio poderá vir a diminuir nos próximos anos.

\section{TÉCNICA DE SOLUÇÃO PROPOSTA}

Visando elevar o nível de serviço da interseção apontada, a Prefeitura Municipal da Serra elaborou projeto de uma passagem em nível inferior na Avenida Norte Sul. Assim sendo, a interseção entre as duas avenidas mencionadas não seria mais realizada em mesmo nível, reduzindo as paradas causadas por semáforos e permitindo o desenvolvimento de maiores velocidades para os usuários que não têm a intenção de acessar a Avenida João Palácio ou acessar a Avenida José Rato.

O projeto tem como objetivo eliminar o conflito entre os veículos cujas viagens não se findam no referido trecho da Avenida Norte Sul. Tais veículos seguiriam em pistas centrais que mergulhariam na via, à aproximadamente sete metros abaixo da superfície, garantindo que os mesmos sigam seus respectivos trajetos sem qualquer interferência dos veículos que cruzam a referida Avenida, como vem acontecendo. Com menos um movimento conflitante, abre-se espaço para a reprogramação semafórica que, aliada à geometria do projeto, diminui o tempo despendido nos movimentos de acesso às vias perpendiculares à Norte Sul. A Figura 4 evidencia os novos movimentos mencionados, assim como o mergulhão da via. 
Figura 3: Projeto de intervenção para as Avenidas João Palácio e Norte Sul

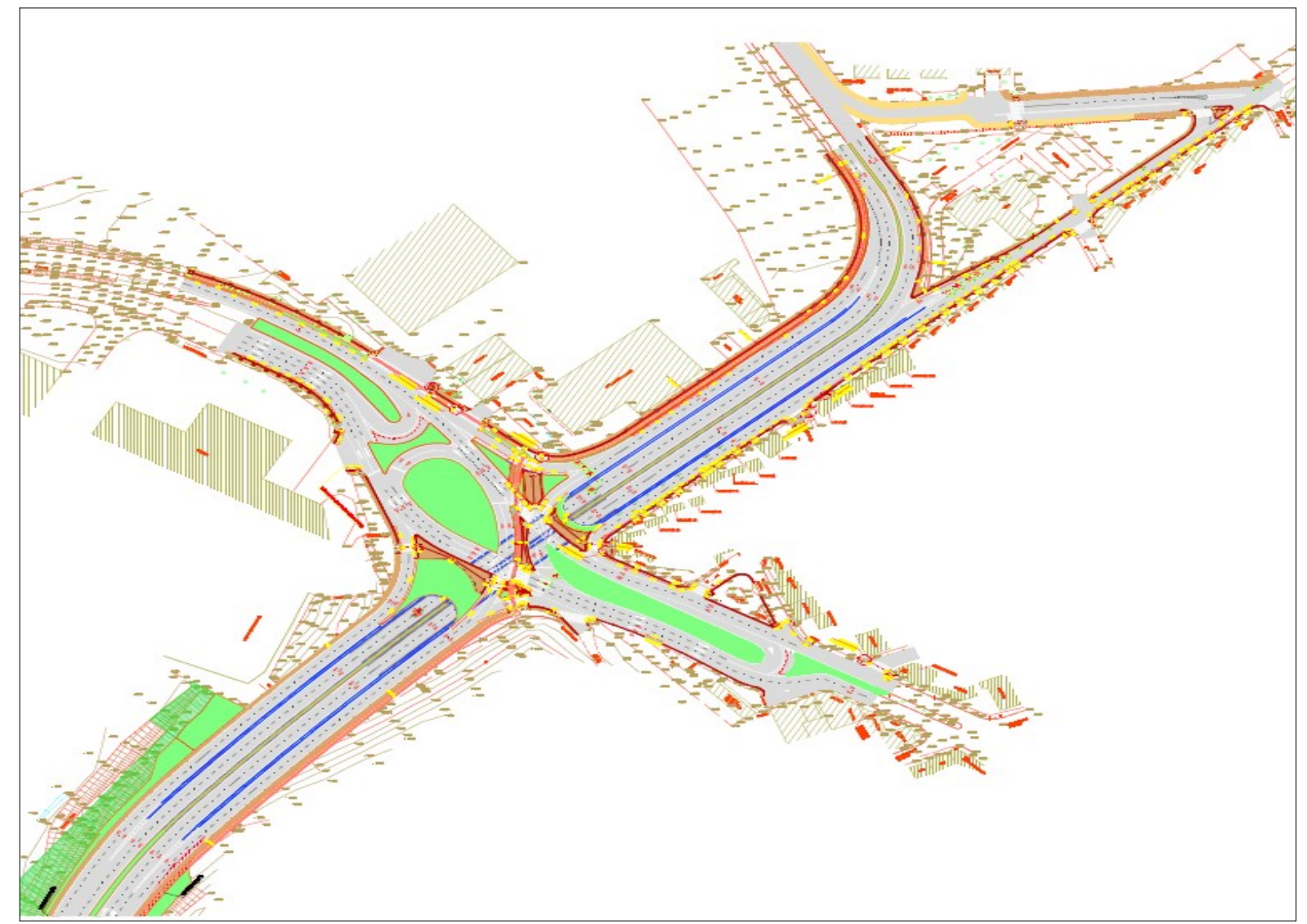

Fonte: Prefeitura Municipal da Serra

\section{CENÁRIOS ANALISADOS}

A avaliação dos impactos sobre a capacidade de tráfego e nível de serviço operacional para interseções urbanas utilizando o software de simulação foram realizadas para dois cenários, ambos para o ano de 2033, considerando diferentes arranjos geométricos e operacionais: a geometria atual (cenário 01) e a geometria proposta pelo projeto da Prefeitura Municipal da Serra (cenário 02).

Como a interseção possui diversos movimentos que deveriam ser analisados, foram criadas três grandes áreas de análise, chamadas de nós. Os nós têm a capacidade de aglutinar os dados daquela região contida dentro dos seus limites, retornando dados de filas máximas, consumo de combustível, emissão de gases, atrasos, nível de serviço, entre outros. Após os resultados de cada um dos movimentos contidos em seu interior, retorna um valor geral, levando em consideração todos os referidos movimentos, possibilitando uma análise macro da região. Os nós 01, 02 e 03 estão representados na Figura 4 abaixo. 
Figura 4: Localização dos nós avaliados para a geometria atual

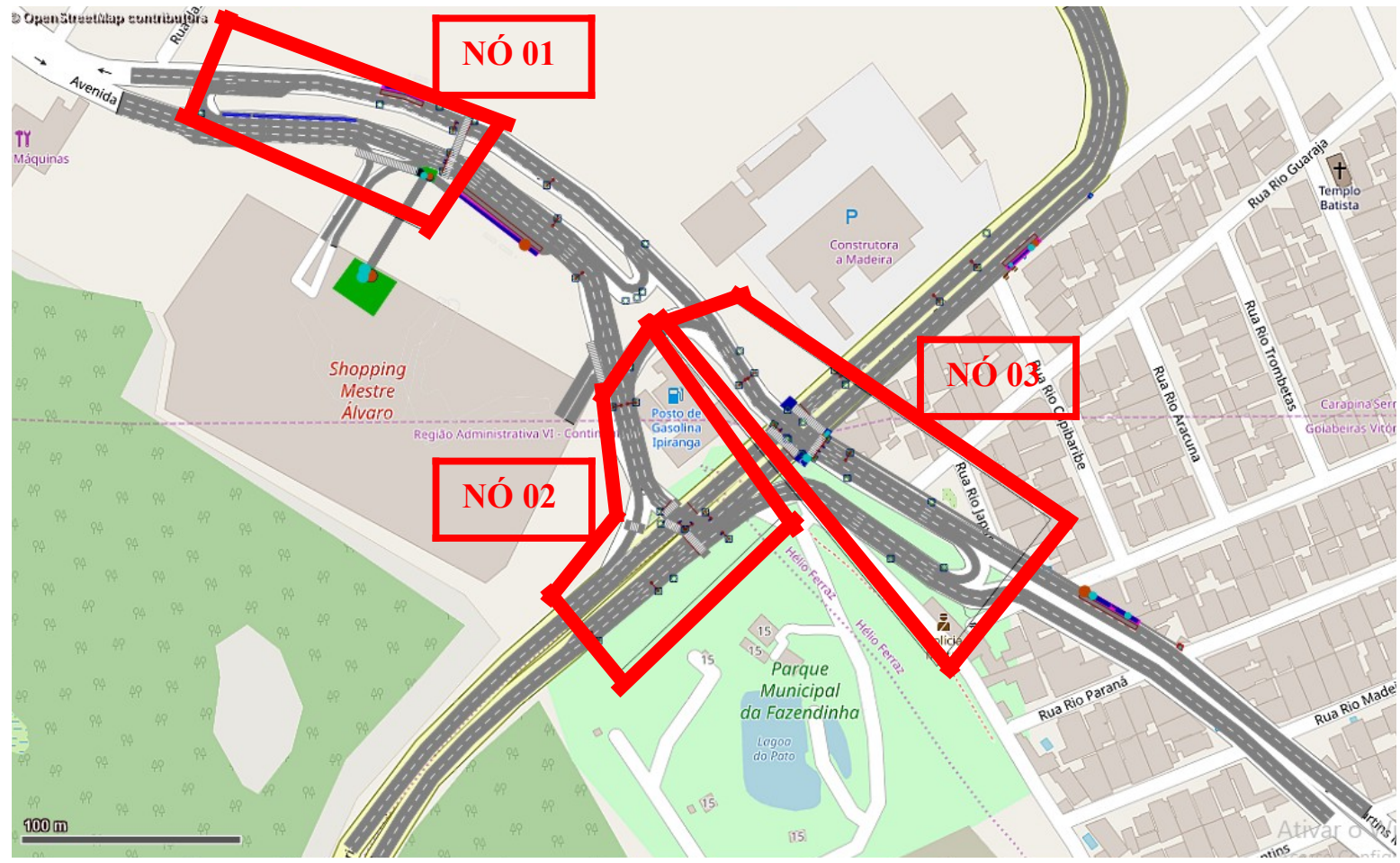

Fonte: PTV Vissim

\section{ANÁLISES E DISCUSSÕES}

A interseção das Avenidas João Palácio e Norte Sul possui um grande volume de veículos que a utilizam com frequência, mas que, nos últimos anos, vem apresentando queda no nível de serviço. Como já evidenciado anteriormente, a localização geográfica, a existência de polos geradores de viagens e o crescimento natural da frota de veículos no município impactaram diretamente nas condições de tráfego a que os usuários estão submetidos.

Dessa forma, as análises dos arranjos geométricos visam destrinchar comparativamente cada um dos itens que caracterizam as vias no que tange ao seu desempenho e atendimento aos usuários que ali trafegam. O software PTV Vissim retorna, após cada uma das simulações, dados como tempo de espera, nível de serviço, consumo de combustível, comprimento de filas, quantitativo de veículos, entre outros dados que serão analisados e discutidos neste capítulo.

A análise se concentrará nos resultados obtidos após a realização das microsimulações, comparando os dados da simulação da geometria atual com as simulações realizadas com a geometria proposta pela Prefeitura Municipal da Serra.

A apresentação dos resultados comparativos será realizada através de gráficos de coluna, possibilitando a visualização macro dos resultados obtidos.

\subsection{Geometria Atual $x$ Projeto}

As simulações da geometria atual (Cenário 01) e a sugerida pelo projeto da Prefeitura Municipal da Serra (Cenário 02) foram simuladas para o ano de 2033, com os resultados sendo apresentados ao longo deste item. 


\subsubsection{Nível de Serviço}

Figura 5: Nível de serviço médio dos nós para a geometria atual e a de projeto

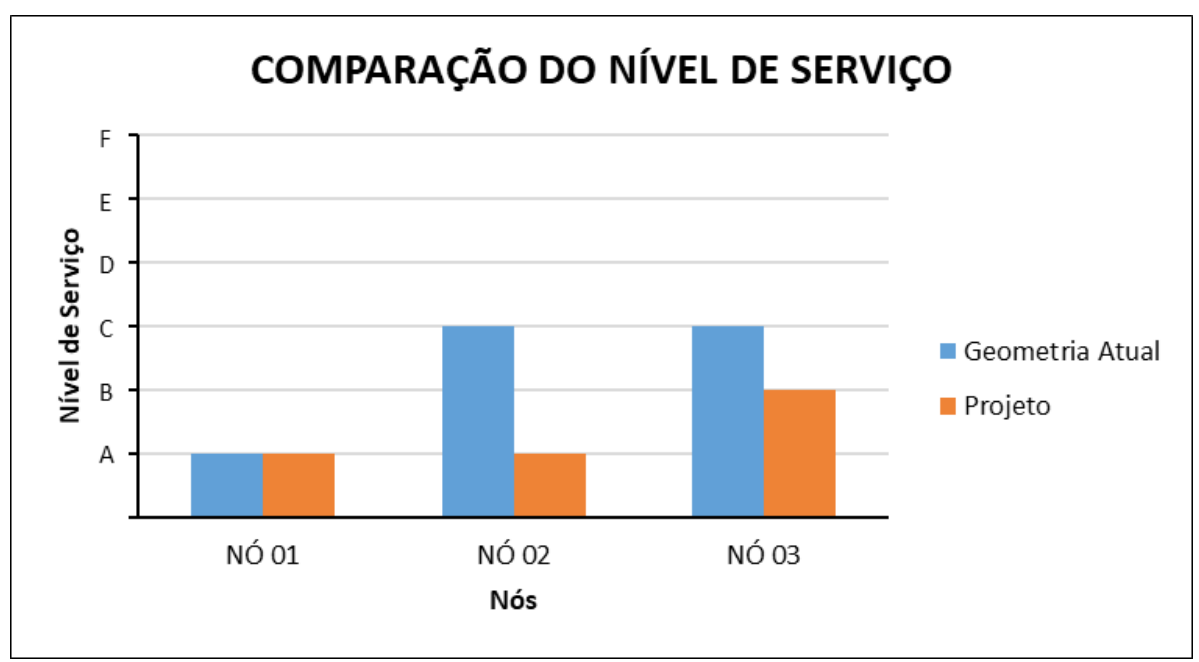

Fonte: $\mathrm{O}$ autor

Pela Figura 5, verifica-se que o nó 01 manterá o nível de serviço A. Os nós 02 e 03 melhorarão o seu nível de atendimento aos usuários, com destaque para o nó 02, que possuiria nível de serviço C em 2033 e que com a execução do projeto já elaborado, passará a possuir nível de serviço A.

Portanto, o projeto proposto melhorará o nível de serviço geral do local de implantação quando comparado ao estado atual.

\subsubsection{Comprimento de Filas}

Inicialmente, procedeu-se a análise comparativa entre o comprimento das filas. Para esse dado, foi utilizado o comprimento de todas as filas contidas dentro de cada um dos três nós apresentados anteriormente nesse trabalho.

Figura 6: Comprimento de filas no interior dos nós para a geometria atual e a de projeto

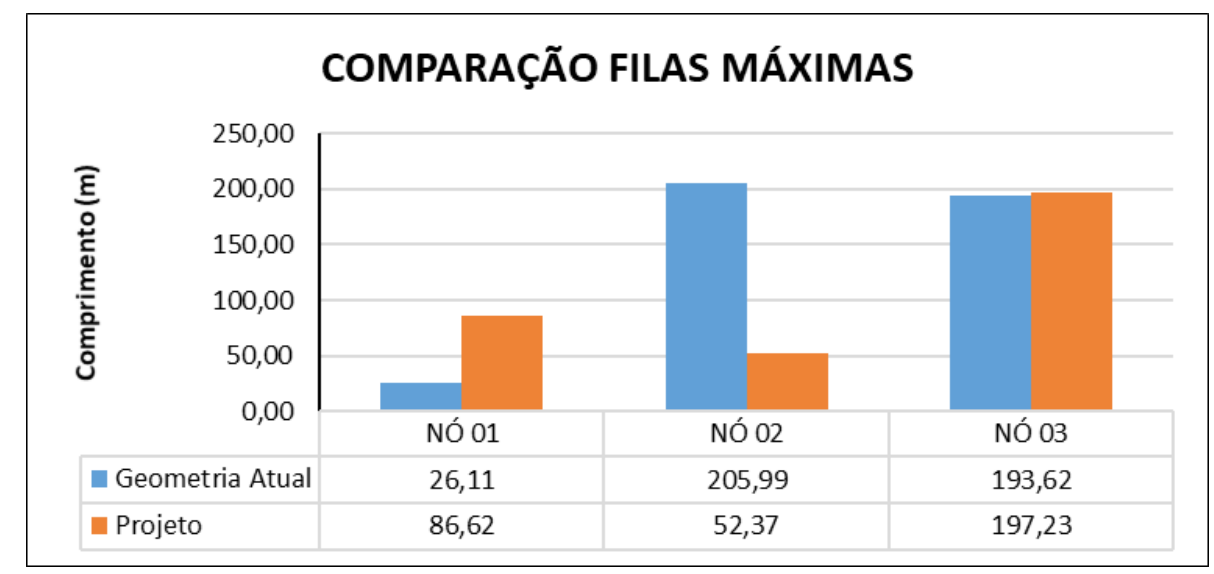

Fonte: $\mathrm{O}$ autor

Pela Figura 6, constata-se que há uma redução drástica no comprimento total das filas contidas no nó 02, devido a retirada de um movimento conflitante que existe atualmente, no caso, o dos veículos que permanecerão na Avenida Norte Sul com os veículos oriundos da Avenida João Palácio e que desejam acessar a Avenida Norte Sul ou a Avenida José Rato. 
Constatou-se, o entanto, um aumento no comprimento das filas existentes no nó 01 e nó 03. Após análise dos dados de contagem do software, verificou-se que um maior volume de veículos faz os trajetos de acesso aos referidos nós no mesmo período analisado na geometria atual. De maneira simplificada, os dados apontam que mais veículos conseguem acessar os nós 01 e 03 em um menor espaço de tempo devido, principalmente, às pistas laterais da Avenida Norte Sul, propostas pelo projeto.

O nó 01, localizado próximo ao shopping recebe mais veículos quando analisada a geometria proposta em projeto. E, sem a alteração nos tempos de ciclo para compensar o maior volume de veículos no trecho, há uma maior retenção dos mesmos nos semáforos contidos no interior do referido nó.

O nó 03 apresenta um ligeiro aumento no comprimento das filas. No entanto, como exposto anteriormente, há um maior número de veículos acessando a via no trecho analisado pelo nó 03. Então, há relativa melhora do ponto de vista quantitativo que deve ser considerado conjuntamente com o comprimento da fila. A análise conjunta entre os dois comportamentos evidencia que há uma compensação do aumento no comprimento através do maior número de veículos que estão realizando o movimento no trecho em menor espaço de tempo.

\subsubsection{Comprimento de Filas nos Semáforos}

Foram analisados os comprimentos das filas diretamente geradas pelos semáforos existentes em cada um dos nós.

Figura 7: Comprimento de filas geradas pelos semáforos para a geometria atual e a de projeto

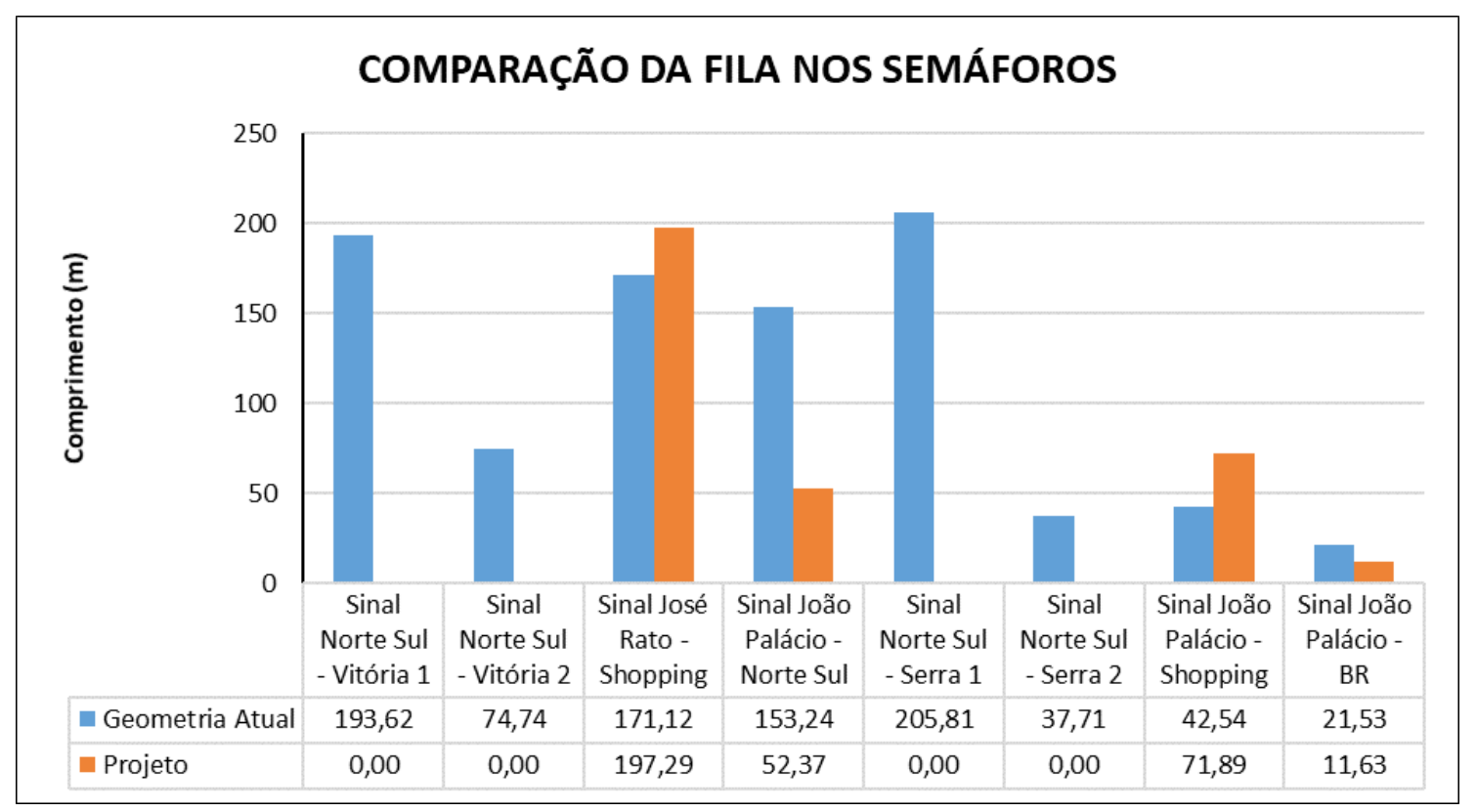

Fonte: $\mathrm{O}$ autor

Inicialmente, cabe salientar que a execução do mergulhão eliminou qualquer geração de filas para alguns movimentos. Os veículos oriundos da Avenida Norte Sul sentido Serra não mais encontram retenção por conta de semáforos para acessarem a Avenida José Rato, devido à pista lateral (Sinal Norte Sul - Serra 1). O mesmo raciocínio se aplica para os veículos oriundos do sentido inverso da Avenida Norte Sul e que desejam acessar a Avenida João Palácio sentido Serra (Sinal Norte Sul - Vitória 1).

Os veículos que desejavam permanecer o curso na Avenida Norte Sul sejam sentido 
Serra ou Vitória, não possuem nem mesmo a interseção em nível, já que a execução do mergulhão permitirá que não sejam impactados com formação de filas devido aos semáforos. Dessa forma, as retenções geradas pelo "Sinal Norte Sul - Vitória 2" e pelo "Sinal Norte Sul - Serra 2", deixam de existir.

Infere-se da Figura 7 que há o aumento na fila dos semáforos localizados na Avenida José Rato (Sinal José Rato - Shopping) e do semáforo localizado na Avenida João Palácio em frente ao shopping (Sinal João Palácio - Shopping). Isso se deve ao fato já evidenciado no item 6.1.2, em que devido às alterações de geometria da via, uma maior quantidade de veículos consegue alcançar os semáforos em um menor período, aumentando o comprimento das filas nos mesmos.

No entanto, constatou-se também uma redução no comprimento da fila gerada pelo semáforo localizado na Avenida João Palácio sentido BR 101.

Pelo exposto, verificou-se que houve drástica redução nos comprimentos das filas geradas pelos semáforos no projeto proposto. De fato, ocorreram dois aumentos (Sinal José Rato - Shopping e Sinal João Palácio - Shopping), mas que são explicados pela maior quantidade de veículos que conseguiram de aproximar dos mesmos em um menor espaço de tempo.

\subsubsection{Atrasos nas Interseções Semaforizadas}

O software PTV Vissim analisa os atrasos médios dos veículos nos semáforos. A análise leva em consideração o tempo gasto pelo veículo para percorrer o seu trajeto sem qualquer interrupção por conta do tráfego no local e o que de fato o veículo despende para realização de seu trajeto.

Figura 8: Atrasos dos veículos para a geometria atual e a de projeto

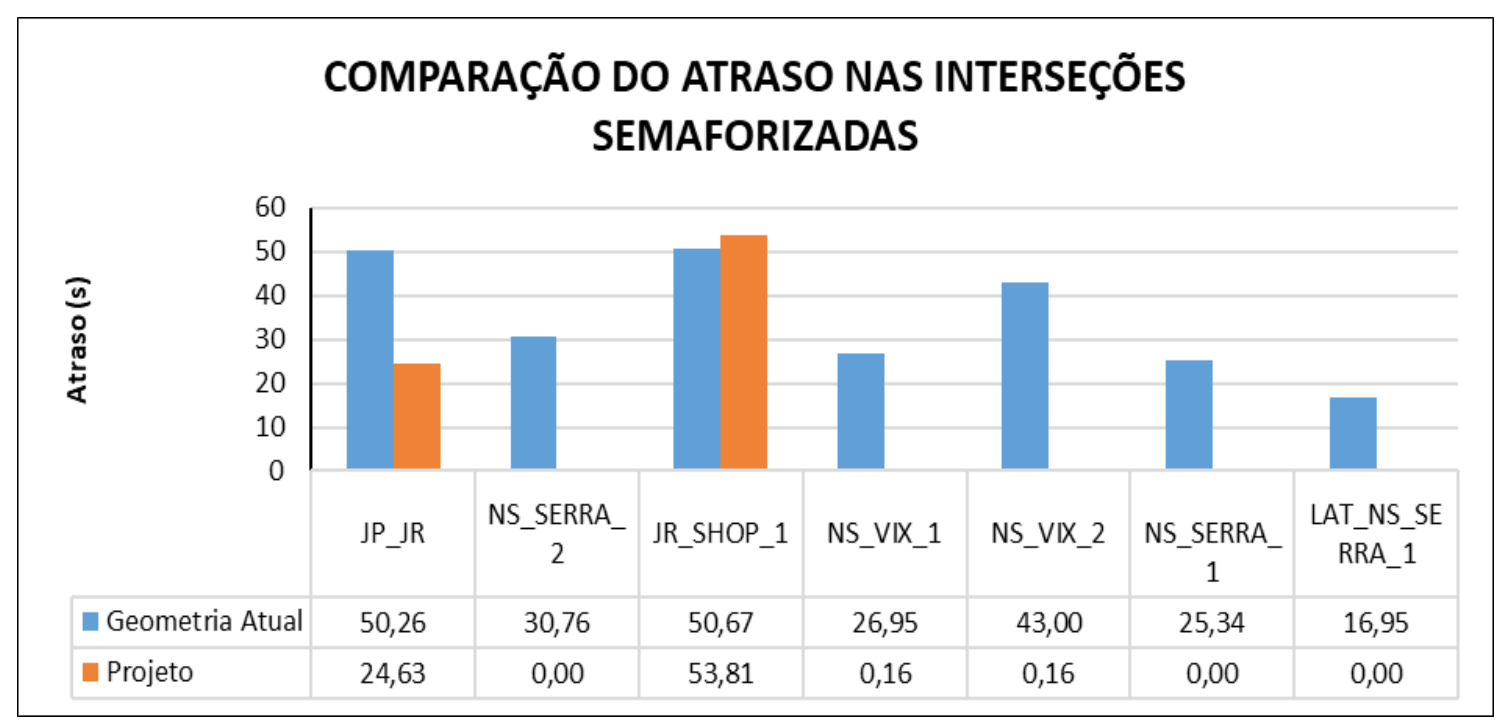

Fonte: $\mathrm{O}$ autor

Verifica-se na Figura 8 a redução drástica nos tempos médios de atraso dos veículos. Apenas o movimento dos veículos provenientes da Avenida José Rato e que foram em direção à BR 101 sofreu aumento, ainda assim, bem ligeiro à situação atual.

Portanto, novamente o projeto proposto para o local de análise desse estudo apresenta melhorias consideráveis em relação ao estado atual da via no que tange aos atrasos médios na realização dos movimentos dos automóveis.

\subsubsection{Consumo de Combustível}

Foram analisadas as emissões de COx, VOx e NOx. As emissões foram agrupadas 
nos nós de origem, sem distinção acerca da composição e contribuição de cada um dos gases, pois entendeu-se ser de mais valia o aspecto macro do referido dado.

Figura 9: Emissão de gases no interior dos nós para a geometria atual e a de projeto

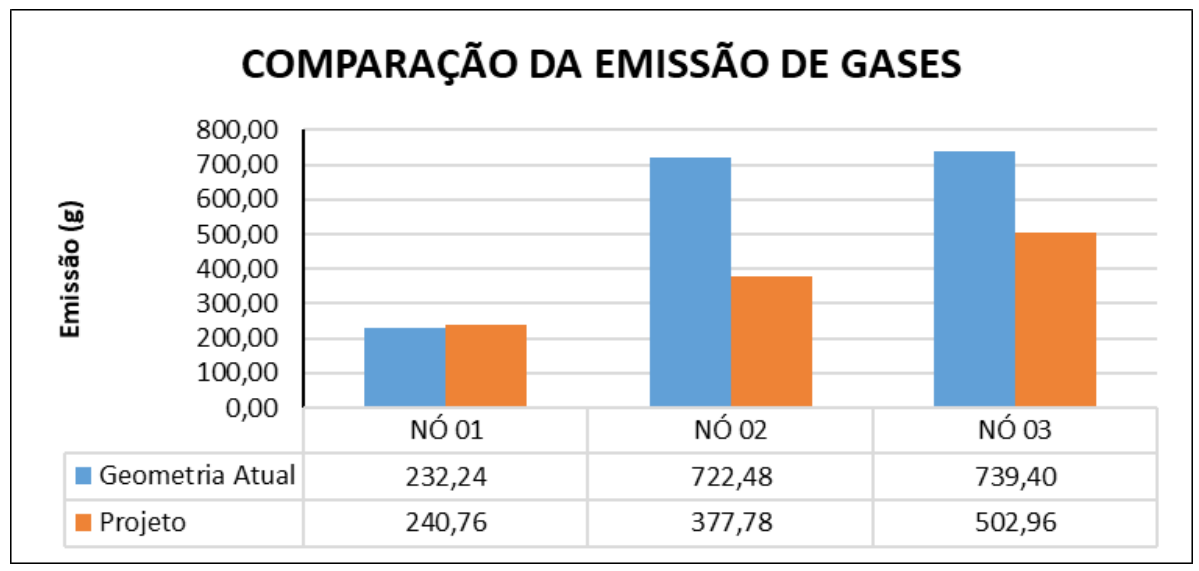

Fonte: $\mathrm{O}$ autor

Verifica-se na Figura 9 um ligeiro aumento na emissão de gases no nó 01 . Constatou-se uma redução considerável na emissão de gases por parte dos automóveis nos nós 02 e 03, por conta da melhora nos níveis de serviço das vias que os compõe.

A análise global da emissão comparativa dos gases, infere-se que a geometria proposta pela Prefeitura Municipal da Serra atua em benefício da redução da emissão de gases que geram o efeito estufa e, consequentemente, é uma solução mais benéfica do ponto de vista ambiental, por ser menos agressiva do que o estado de emissões atual nas vias analisadas.

\subsubsection{Consumo de Combustível}

Figura 10: Consumo de combustível no interior dos nós para a geometria atual e a de projeto

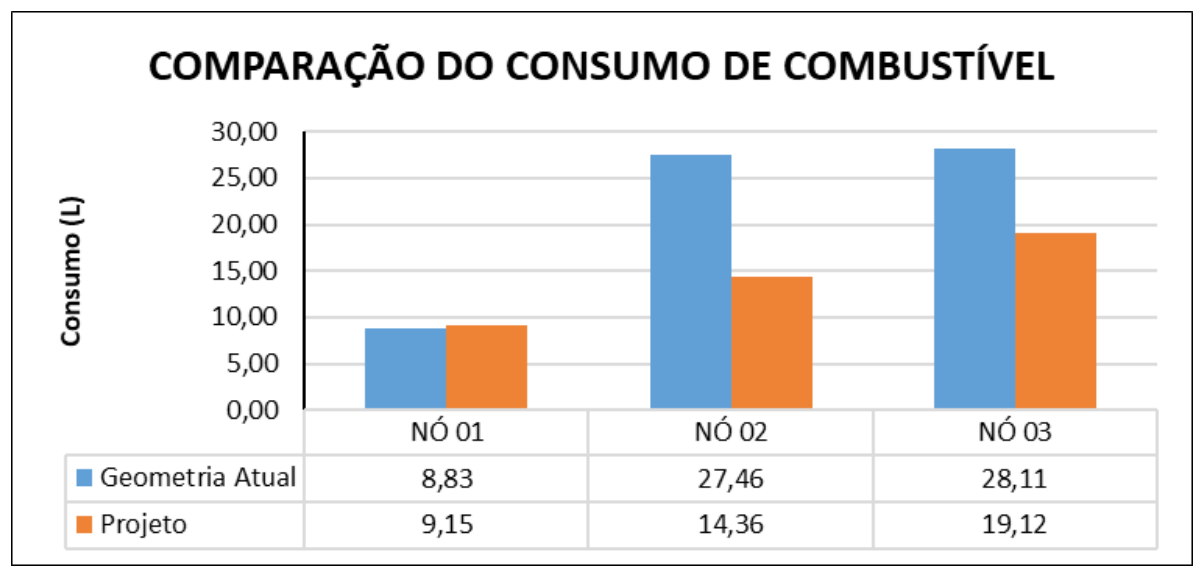

Fonte: O autor

Constata-se na Figura 10 um ligeiro aumento de consumo de combustível pelos veículos no interior do nó 01 , fato esperado devido ao aumento de volume e de filas no referido nó. No entanto, houve redução considerável no consumo de combustível nos nós 02 e 03.

Pelo exposto, fica evidenciado que o ligeiro aumento de combustível no nó 01 na geometria proposta pela Prefeitura da Serra não é o suficiente para descredenciar a proposta. As reduções verificadas nos nós 02 e 03 são consideráveis e demonstram a melhoria do item 
analisado, encontrando, portanto, melhores condições no projeto do que na geometria atual da interseção.

Figura 11: Vista geral da simulação da geometria atual da interseção com a frota de veículos de 2033

Fonte: PTV Vissim

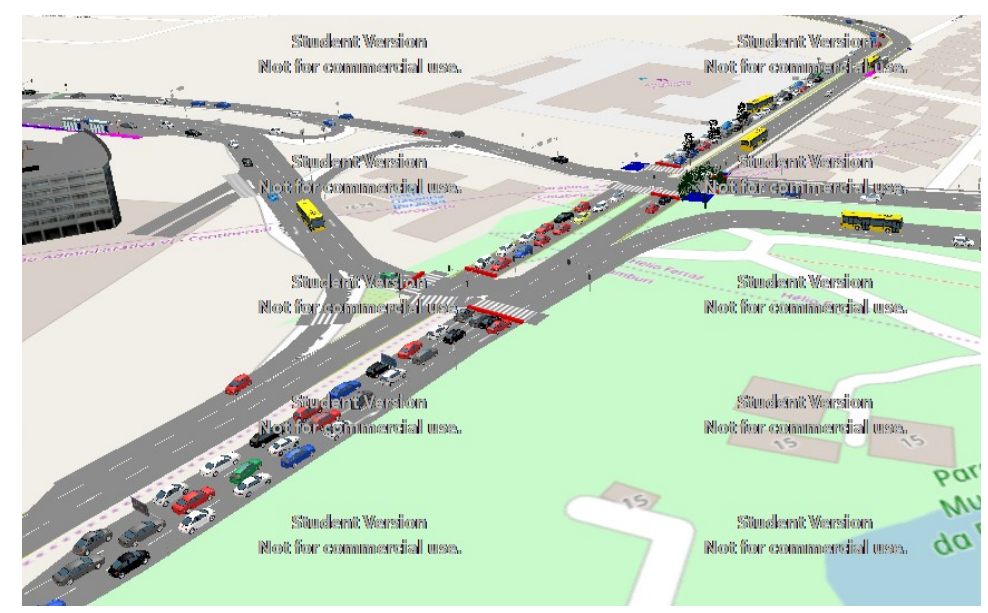

Figura 12: Vista geral da simulação da geometria proposta pela Prefeitura com a frota de veículos de 2033

Fonte: PTV Vissim

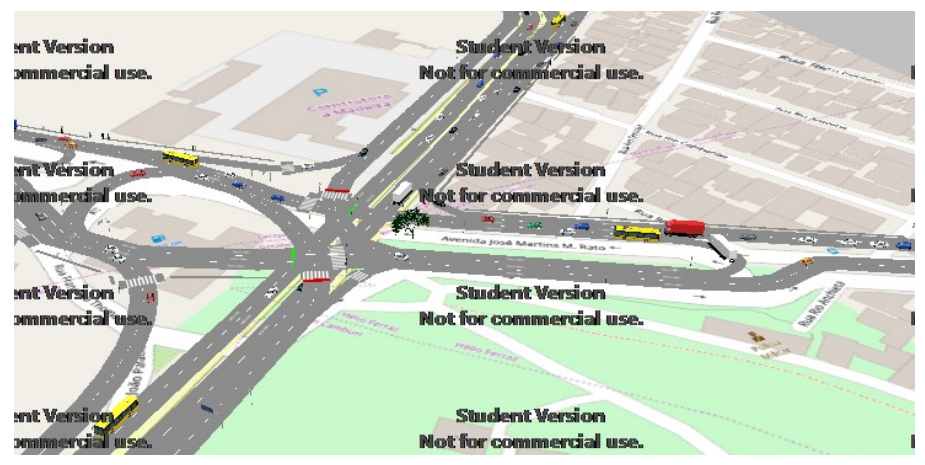

\section{CONCLUSÃO}

As microsimulações realizadas possibilitaram a avaliação dos impactos sobre a capacidade de tráfego e nível de serviço operacional de diferentes arranjos geométricos para a interseção das Avenidas João Palácio e Norte Sul para o ano de 2033. A Prefeitura Municipal da Serra verificou que a existência de um PGV e o crescimento econômico pelo qual passou o município nos últimos anos têm gerado impactos negativos na referida interseção.

Inicialmente, foi avaliada a geometria atual da interseção, caracterizando o estado da via e evidenciando a piora dos níveis de serviço até o ano horizonte de 2033, com as vias não apresentando níveis razoáveis, indicados pelo HCM, evidenciando a necessidade de implantação do projeto elaborado pela Prefeitura.

Em seguida, foi realizada a simulação com a geometria contida no projeto disponibilizado pela Prefeitura, sem alterações nos tempos dos semáforos em relação aos atuais. Foi verificado que o projeto atende ao seu intuito, visto que os níveis de serviço até o ano de 2033 poderiam ser mantidos em A, a despeito do crescimento natural da frota de veículos no município e atendendo aos requisitos propostos pelo HCM. No entanto, constatou-se que alguns movimentos ainda não estavam possibilitando uma utilização satisfatório para os veículos, principalmente para os oriundos da Avenida José Rato e que 
direcionavam à Avenida João Palácio sentido BR 101, que pode ser solucionado com o aumento no tempo de verde para os veículos que fazem esse movimento.

Para a realização de estudos futuros, recomenda-se a realização de estudos aprofundados para se determinar a projeção de crescimento da frota de veículos e a expansão da área de análise da interseção até a BR 101, sendo a Avenida José Rato também avaliada no estudo. A execução do viaduto próximo ao hospital e a implementação do BRT na BR 101, projetos do Governo do Estado do Espírito Santo, devem ser levados em consideração, tendo o estrangulamento da via e o desvio de veículos para a interseção objeto deste trabalho avaliadas de maneira mais detalhada.

\section{REFERÊNCIAS BIBLIOGRÁFICAS}

[1] AGUIAR, F.; CRUZ, M. M. C.; MORAIS NETO, G. C.; BERTOLDE, A. I.. (2017) Traffic quality Index to intersections considering fuel efficiency. International Journal of Sustainable Building Technology and Urban Development, v. 8, n. 2, p. 153-162.

[2] ARAÚJO, A. M. e NETO, M. M. C. (2018) Calibração do modelo de aceitação de brechas em interseções urbanas com o microssimulador de tráfego VISSIM. Transportes, v. 26, n. 3, p. 25-38.

[3] BRASIL. Departamento Nacional de Infraestrutura de Transportes, DNIT. Manual de Estudo de Tráfego. Rio de Janeiro, RJ, Brasil, 2006.

[4] BRASIL. Departamento Nacional de Trânsito (DENATRAN). (Comp.). Relatório Estatístico. $2018 . \quad$ Disponível em: <http://www.denatran.gov.br/index.php/estatistica/237-frota-veiculos>. Acesso em: 27 maio 2019.

[5] ESPÍRITO SANTO. Departamento Estadual de Trânsito do Espírito Santo (DETRANES). Anuário Estatístico de Trânsito do Detran-ES. 2016. Disponível em: $<$ https://detran.es.gov.br/anuarios-2>. Acesso em: 27 maio 2019.

[6] HARREL, C.; GHOSH, B.K.; BOWDEN, R. Simulation Using Promodel. $3^{\mathrm{TM}}$ ed. Boston: McGraw-Hill, 2000.

[7] Highway Research Board, HRB. Highway Capacity Manual. Washington, D.C., EUA, 2010.

[8] MARTÍN, L. E.; BANDEIRA, T. P., PINTO, D. G.; NETO, M. M. C. (2019). Atraso de pedestres em travessias semaforizadas: uma comparação entre as modelagens pelo HCM e pelo microssimulador VISSIM. Transportes, v. 27, n. 1, p. 128-140.

[9] PORTUGAL, L. S. Simulação de tráfego - Conceitos e Técnicas de Modelagem. Rio de Janeiro: Interciência, 2005.

[10] PTV Vissim. Version 10. [S.l.]: PTV Group, 2018. Disponível em: <https://www.ptvgroup.com/en-us/solutions/products/ptv-vissim/>. Acesso em 29 de maio de 2019.

[11] SASAKI, M. W.; FILHO, F. E. M.; LIRA, J. A. (2017) Avaliação da mudança da velocidade máxima permitida e sua influência no desempenho da segurança viária em um corredor urbano. Anais do XXXI Congresso Nacional de Pesquisa e Ensino em Transportes, ANPET, Recife. 
[12] SERRA. Câmara Municipal da Serra. A Serra, a região metropolitana e o Espírito Santo. 16 de Dezembro de 2005. http://www.camaraserra.es.gov.br/pagina/ler/1016/aserra-a-regiao-metropolitana-e-o-espirito-santo (acesso em 22 de Agosto de 2019). 